\title{
LOS OMOPLATOS GRABADOS DE LA CUEVA \\ DE ALTAMIRA
}

RiCARDO MONTES BERNARDEZ

\section{Comentario estilístico y artístico}

Los omoplatos grabados de Altamira son testimonio de la vida espiritual, sensitiva y artística de nuestro hombre altamirense, en concreto, y paleolítico en general. Muestran aspectos profundos y misteriosos que llevan a un terreno en el que lo connatural alcanza valores expresionistas pocas veces logrados por el hombre a lo largo de su azarosa historia.

El hombre se nos pierde en la oscuridad de los tiempos, pero he aquí que deja plasmada la imagen de lo que para él forma parte vital de su existencia, en todos los medios a su alcance: paredes, huesos, etc.; con este legado dicha oscuridad se convierte en una ténue luz que permite internarse en el campo de las interpretaciones y deducciones, al objeto de aclarar, un poco más, lo que fue su vida mental, religiosa y social.

En la observación de estos siete omoplatos, uno no puede por menos de cuestionarse la razón de estas creaciones, más artísticas que prácticas a primera vista, su posible utilidad, la elección de estas partes tan concretas de la osamenta animal, casi exclusivamente ciervas, su sentido quizás ritual y religioso, preguntas todas ellas difíciles de contestar todavía pero que no se pueden eludir.

Aparecen, en principio, como maravillosas expresiones artísticas propiamente dichas, de nuestros antepasados, sorprendiendo por su intensidad y fidelidad naturalista, así como por su sentido intuitivo, fruto de una observación y un poder de captación propios de una mente desarrollada en gran medida y de una sensibilidad especial.

El hombre debía haber extendido su necesidad expresiva a una escala considerable, demostrado por la existencia de estos omoplatos y, caso de que no fuera así, la presencia de estas manifestaciones artísticas hace pensar que, al menos, en su ánimo había algo más que la preocupación representativa de la fauna; incluso se podría pensar en ensayos sobre estos huesos para posteriores realizaciones expresivas de todo 
tipo, lo que lleva a suponer la observación de ciertas superposiciones que se pueden ver en alguno de los omoplatos. En cambio, otras de estas piezas hacen reflexionar sobre la existencia de autonomía propia como expresión artística ya en sí misma.

En general, se aprecia en la realización de estos grabados una seguridad en el trazo y un dominio del sentido rítmico en la línea, poco comunes, que denotan la capacidad y conocimientos técnicos, ya ensayados, quizás en otros materiales posiblemente perecederos, que tenían sus artífices.

Sorprende cómo se logró una pureza tal de línea y una justeza tan enorme en la forma, sin titubeos, temblores o vibraciones que denoten una duda o inseguridad, máxime empleando incómodos buriles de silex, tan distintos de los que se utilizan actualmente. Se debió contar, sin duda, con una retentiva y destreza singulares.

Si existió o no en este alborear del arte una serie de talleres donde se realizaran estas obras es motivo de interés aunque difícilmente sostenible, si se quisiera ser categórico, ya que hoy no deja de ser una teoría más, basada en la apreciación de que los omoplatos de El Castillo y de Altamira parecen responder a una muy determinada escuela "provincial» que se iniciaría en el Solutrense final y acabaría en el Magdaleniense inicial, diferenciándose del resto de los yacimientos con hallazgos de este tipo. Esta coincidencia podría ser el fruto de una tradición, o bien de una convergencia. punto que quedaría más esclarecido con un completo estudio de las dos cuevas. Caso de resultar una divergencia, cabría preguntarse el por qué se dio en lugares tan cercanos y por qué no se dio en el resto del área franco-cantábrica.

Volviendo al comentario de estas siete piezas, objeto de nuestro estudio, comencemos por analizar el omoplato n. 1 y observemos como el trazado de la línea se ajusta mejor a lo que creemos se podía realizar con cierta facilidad, teniendo en cuenta los medios de que disponía el hombre del Solutrense, que en las otras piezas. La cabeza aparece ligeramente alzada, en posición de alerta, vital, lo que denota la capacidad de observación y captación del artista ejecutor. Su dibujo interno es seguro y definitivo, dando al animal un sentido del volumen bien conformado. Su realizador debió ser un hombre ya experimentado en la utilización del material y en las representaciones zoomorfas.

En el segundo omoplato vemos que la intensidad expresiva no es tan importante, la línea se hace más blanda y la disposición de la cabeza es más simple.

En el tercero encontramos una sorprendente e interesantísima cabeza que muestra una gran expresividad con detalles de gran seguridad. La cabeza produce la impresión de hallarse en movimiento, el animal la le- 
vanta como para otear el horizonte y el artista parece haberla realizado en un escorzo lateral.

El cuarto omoplato observa una yuxtaposición de figuras, en la que si no las intentamos separar visualmente, bien pudiera imaginarse una intrincada cacería, en la que animales y flechas se mezclan en un todo homogéneo aunque poco claro. La cierva de la parte superior es, sin lugar a dudas, la más intensa y la que ofrece más movimiento, con su morro puntiagudo y una línea graciosa y bella. Su sentido rítmico es completo. El resto de las representaciones aparecen más sintetizadas.

El omoplato $n .^{\circ} 5$ ofrece poca oportunidad al comentario debido a su casi total fractura y, aunque su reconstrucción puede ser acertada, creemos preferible pasarla un poco por alto.

El sexto omoplato muestra un dibujo menos rico y la figura es más estática; asimismo su técnica es más pobre y menos intensa.

En el séptimo y último omoplato se nos ofrece la representación del "pelaje» correspondiente al cuello y papada. Pese a lo poco que puede observarse del total del grabado, se aprecia una técnica de ejecución rica y segura.

Tras este breve comentario de cada uno de estos siete omoplatos podría pensarse que hubo más de una mano realizando los grabados, algo imposible de saber con las técnicas de investigación actuales; sin embargo, hay que tener en cuenta que los números 1 y 3 muestran una misma tensión, aunque expresada de manera distinta. Por su parte, el número 4 y el 5 indican claramente la sensación de movimientos y angulosidad, conceptos distintos a los dos anteriores. Por último, los números 2,6 y 7 reflejan estatismo, distinguiéndose claramente de las representaciones anteriores.

\section{TÉCNICA}

El claroscuro que se aprecia en los grabados de Altamira, obtenido a base de múltiples incisiones, consideramos, como otros autores (Altuna, Apellaniz, 1976, p. 161), que los artistas que los realizaron pretendieron obtener una representación que diera idea de pelaje, imprimiendo así a la figura mayor fuerza. Aunque claroscuro no es el nombre más apropiado para denominar dicha técnica, se emplea por estar consagrado y no poder, de momento, ofrecer otro mejor.

Por su parte, las siete piezas con que contamos en la cueva de Altamira, han sido realizadas a base de un grabado múltiple en el interior del contorno, formando un apretado conjunto de líneas. Esta técnica desaparece, por completo, durante el Magdaleniense, momento cultural netamente distinto del Solutrense en el que las figuras son realizadas mediante trazos concentrados únicamente en la silueta, sin relleno ni 
detalles y, cuando éstos desaparecen, lo hacen de un modo distinto, con otro concepto diferente del que se trató de expresar en las piezas de Altamira o El Castillo.

Los omoplatos que estamos tratando fueron ejecutados con piezas de un solo grosor. Las distintas anchuras de los grabados han sido conseguidas por una repetición del trazo, con gran habilidad y siguiendo una línea sin arrepentimientos, aunque, a veces, se escapa la pieza grabadora debido a la fuerza y presión con que debieron ser ejecutados los trazos.

Al observar una pintura, escultura o cualquier creación artística, los ojos se dirigen siempre en primer lugar a las zonas deterioradas o fracturadas. Por este mismo impulso instintivo, al mirar los grabados, la vista se fija en los espacios en blanco y las zonas de sombreado, que dan la impresión de simular el pelaje, resaltan más. Los trazos múltiples, gracias a los cuales se logra este efecto, se colocan predominantemente en las partes bajas de las figuras: en la zona de la cabeza, los encontramos en la papada, en el cuerpo, se deja en blanco el lomo, etc., partes éstas donde menos pelaje solía tener el animal representado, lo que podría corroborar, en parte, esta idea de figuración intencional de pelo.

Por regla general se observa un naturalismo pleno en estas creaciones, ahora bien, en el omoplato número 4 de Altamira se ven formas netamente angulosas, rasgo más típico de las representaciones de El Castillo, en las que se aprecian esquematizaciones de orejas y nariz, con predominio de estas formas angulosas ya mencionadas.

\section{TEMAS}

La fauna es el motivo exclusivo de los omoplatos grabados de Altamira, destacando un claro predominio de ciervas, ya que contamos con un solo caballo (dudoso), un bisonte (o toro) y ocho ciervas.

En resumen tenemos siete omoplatos con un total de 10 figuras zoomorfas que, en la mayoría de los casos, muestran la cabeza y el arranque del cuerpo. Como dato cuantitativo podemos decir que de las diez representaciones sólo tres miran a la derecha.

No cabe duda de que el animal más representado es aquél del que más restos óseos se han hallado, lo que puede deberse a su gran abundancia.

Precisa el Cervus elaphus un medio forestal, por lo general, de bosque de hoja caduca y, a veces, la zona de contacto entre éste y el bosque de coníferas (G. Echegaray, 1972, p. 171). Vive en un clima preferentemente templado y húmedo, lo que da una idea del medio ambiente en el que se debieron de mover los artífices de Altamira. Sin embargo, no debió ser el bosque el que ocupara toda la extensión de la zona pues, tanto el Equus 
caballus, como el Bos primigenius, que también aparecen representados en los omoplatos, nos hablan con su presencia de espacios abiertos, de pastos que se alternarían con el bosque.

\section{B I B L I O G R A F I A}

Almagro Basch (1976): Los omoplatos decorados de la cueva de El Castillo. Puente Viesgo (Santander). Monografías arqueológicas, núm. 2. Museo Arqueológico Nacional de Madrid.

Altuna-Apellaniz (1976): Las figuras rupestres paleoliticas de la cueva de Altxerri. Guipúzcoa. Munibe, 1-3.

I. Barandiarán, M. (1973): El arte mueble del Paleolitico Cantábrico. Zaragoza.

González EchegaraY: Consideraciones climáticas y ecológicas sobre el Magdaleniense III en el norte de España. Zephyrus, núm. XXIII-XXIV, pp. 167-182. 

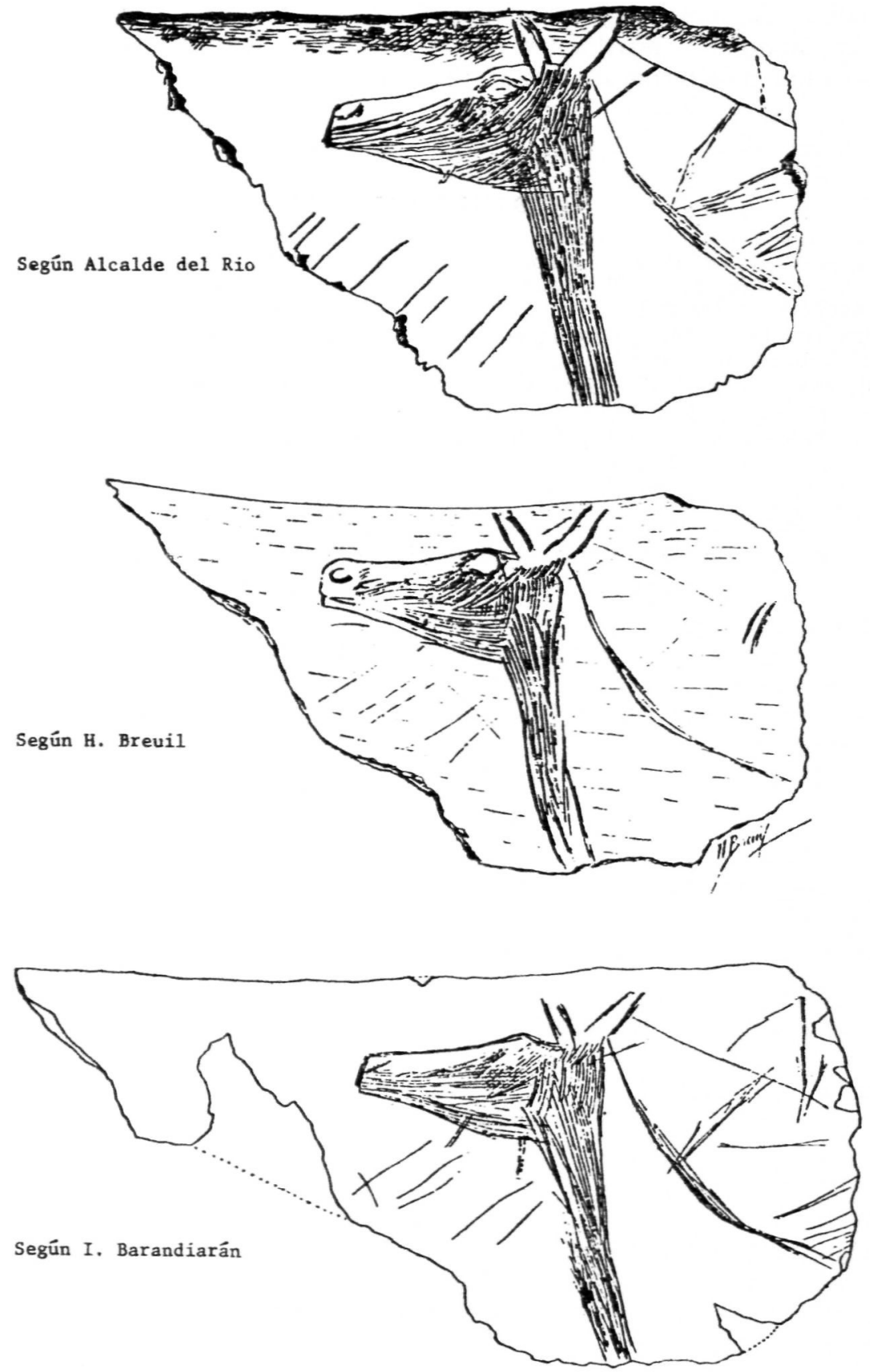

OMOPLATO $\mathrm{N}^{\circ} 1$ 


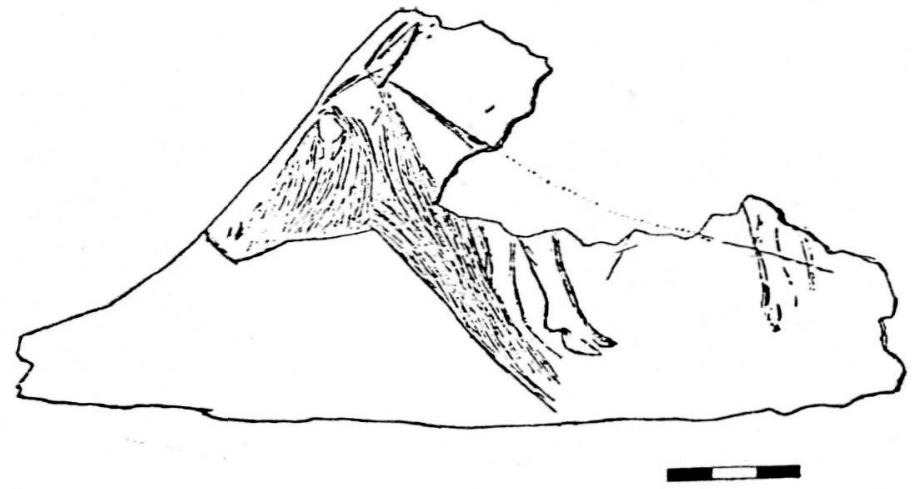

Segứn H. Breuil

OMOPLATO $\mathrm{N}^{\circ} 2$

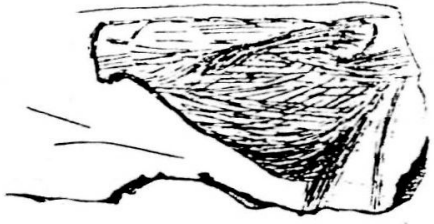

Según Alcalde del Rio

OMOPLATO $\mathrm{N}^{\circ} 3$

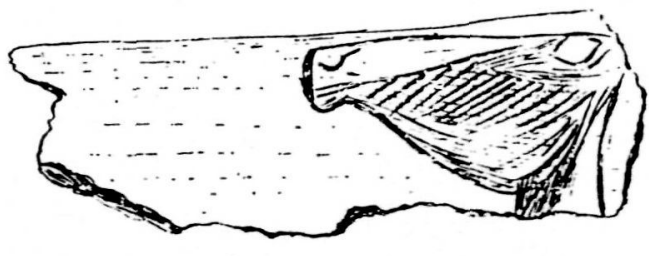

Según H. Breuil

OMOPLATO $\mathrm{N}^{\circ} 3$ 


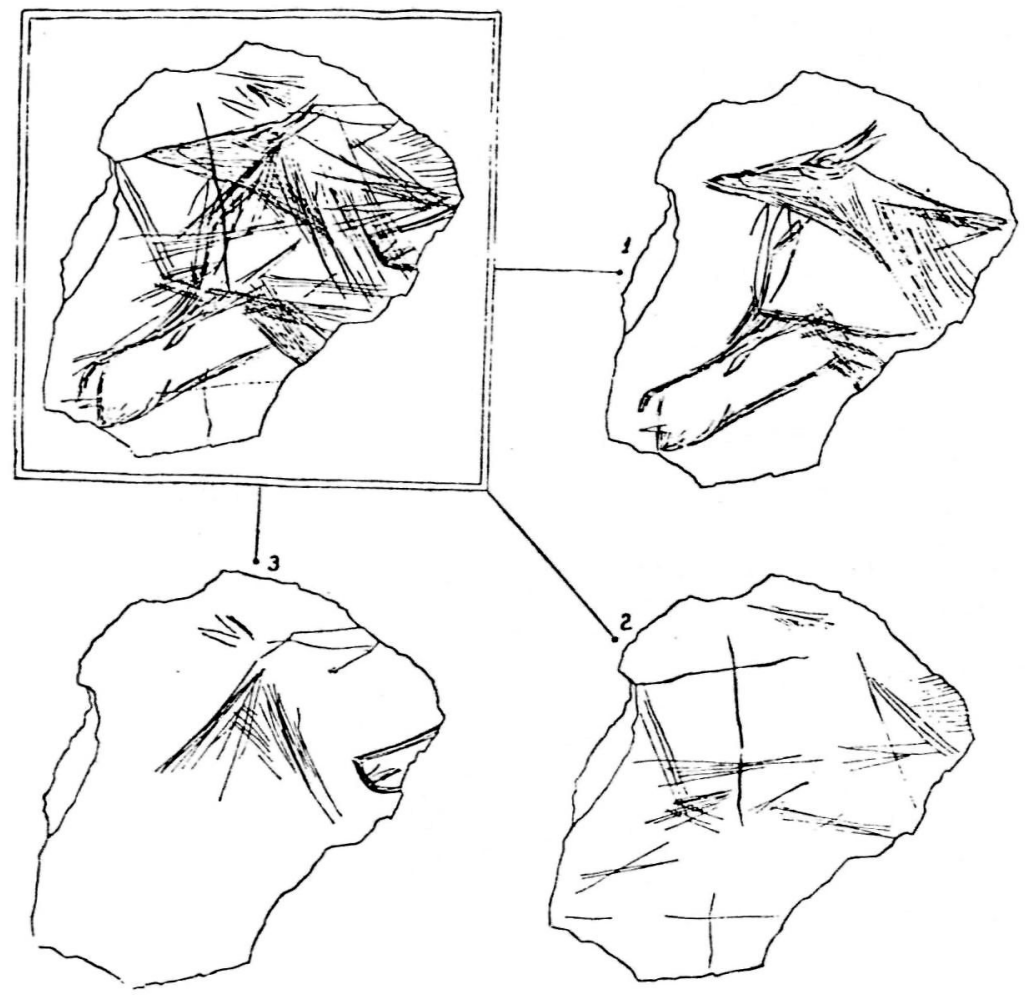

Según I. Barandiàrán

OMOPLATO $\mathrm{N}^{\circ} 4$

Según I. Barandiarán

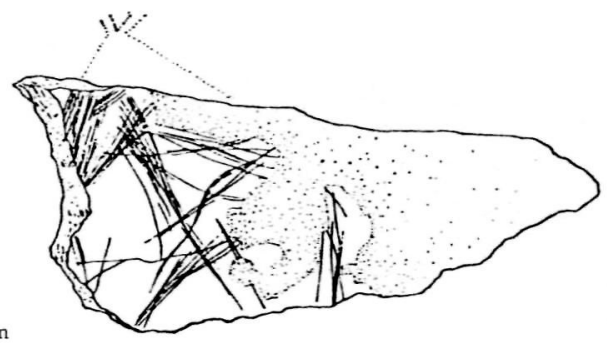

OMOPLATO $\mathrm{N}^{\circ} 5$ 
Según I. Barandiarán

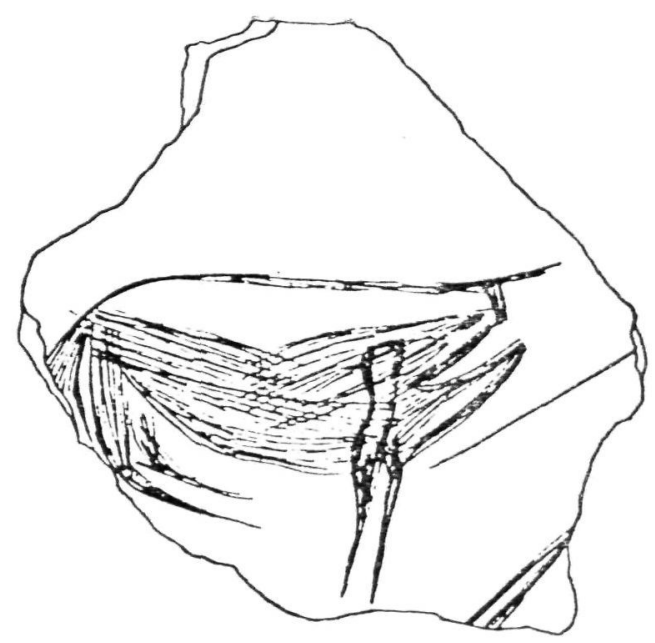

OMOPLATO $\mathrm{N}^{\circ} 6$

Según Alcalde del Rio

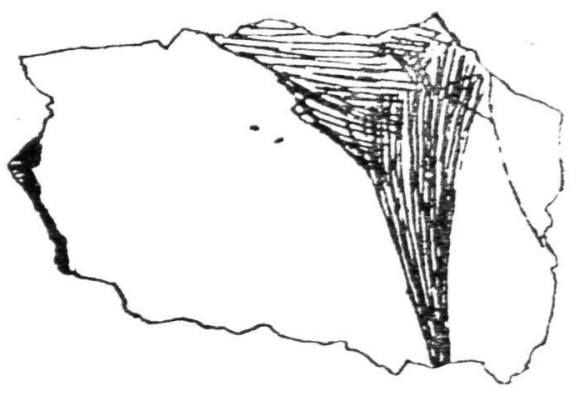

OMOPLATO $\mathrm{N}^{\circ} 7$ 